\title{
Comunidade aprendente de professores que ensinam Matemática nos anos iniciais: uma experiência formativa
}

\author{
Learning community of teachers who teach mathematics in the early years: a \\ formative experience
}

Simone Mumbach

Charles dos Santos Guidotti \begin{abstract}
nos entendimentos de comunidade aprendente (BRANDÃO, 2005; GALIAZZI et al., 2017; FREITAS, 2010). A comunidade de professores em formação desenvolveu atividades formativas de forma síncrona e assíncrona, por meio do Google Sala de Aula, totalizando 40 horas. A partir dessa experiência, assumimos que a formação continuada de professores em comunidade oportuniza discussões, reflexões e partilha de experiências possibilitando o aperfeiçoamento da ação docente.
\end{abstract}

Resumo: Este artigo apresenta a experiência formativa de uma comunidade aprendente de professores que ensinam Matemática nos Anos Iniciais no intuito de estudar, discutir, refletir e compreender as mudanças curriculares propostas pelo Referencial Curricular Gaúcho de Matemática para esta etapa da escolaridade. A proposição formativa fundamenta-se teoricamente

Palavras-chave: Comunidade aprendente. Formação continuada de professores. Matemática. Anos Iniciais. Currículo.

Abstract: This article presents the formative experience of a learning community of teachers who teach mathematics in the early years in order to study, discuss, reflect and understand the curricular changes proposed by the Gaucho Mathematical Curriculum Reference for this stage of schooling. The formative proposition is theoretically based on the understandings of the learning community (BRANDÃO, 2005; GALIAZZI et al., 2017; FREITAS, 2010). The community of teachers in training developed training activities in a synchronous and asynchronous way, through the Google Classroom, totaling 40 hours. Based on this experience, we assume that the continuing education of teachers in the community provides opportunities for discussions, reflections and sharing of experiences, enabling the improvement of teaching activities.

Keywords: Learning community. Continuing teacher education. Mathematics. Initial Years. Curriculum.

\section{Introdução}

A educação vive um movimento importante de mudanças curriculares a partir da homologação, em 2017 e 2018, respectivamente, da Base Nacional Comum Curricular (BNCC) e do Referencial Curricular Gaúcho (RCG). A construção da BNCC teve início em 2014 e, a partir
Simone Mumbach Pela Rio Grande de Educação do Rio Grande do Sul e da Secretaria Municipal de Educação de Igrejinha. Rio Grande do Sul, Brasil. iD orcid.org/0000-0002-1857-8922

$\triangle$ profe.simonemumbach@gmail.com

Charles dos Santos Guidotti Doutor em Educação em Ciências. Professor do Programa de Pós-Graduação em Ensino de Ciências Exatas da Universidade Federal do Rio Grande (FURG). Rio Grande do Sul,

orcid.org/0000-0002-5483-1550

$\bowtie$ charles.guidotti@furg.br

Recebido em 06/04/2020 Aceito em 20/04/2020 Publicado em 24/04/2020 
de consultas e audiências públicas, em dezembro de 2017 foi sancionada a versão final. De caráter normativo e elaborada com as contribuições dos profissionais da educação, a BNCC vem ao encontro da legislação vigente, definindo os saberes essenciais que os estudantes devem desenvolver ao longo da Educação Básica. Dessa forma, estudantes das redes municipal, estadual e privada, devem ter as mesmas oportunidades de aprendizagens, independente da rede ou do estabelecimento de ensino a qual pertença.

Neste contexto, a construção dos referenciais estaduais representou a oportunidade de cada território refletir e incorporar suas especificidades a fim de elaborar um documento representativo da realidade local. No Estado do Rio Grande do Sul, o Referencial Curricular Gaúcho foi produzido ao longo de 2018 a partir de estudos realizados pelo grupo de redatores, bem como da participação dos docentes nas consultas públicas. Em dezembro de 20180 documento estadual foi homologado e, a contar de 2019, cabe às Escolas e aos professores a reestruturação de suas propostas pedagógicas com vistas ao alinhamento entre as concepções previstas nestes documentos e a prática docente em sala de aula.

Neste cenário, a formação continuada de professores exerce um papel crucial tendo em vista o desafio de apropriar-se destas mudanças curriculares assim como integrá-las à prática cotidiana nas escolas e nas salas de aula. Entendendo esse importante papel do professor, apresentamos neste artigo uma experiência vivida na formação de uma comunidade aprendente de professores que ensinam Matemática nos Anos Iniciais, com objetivo de problematizar as práticas de sala de aula que norteiam a proposta do Referencial Curricular Gaúcho. Nesse sentido, organizamos a escrita do artigo em seis seções a contar da introdução. Na seção dois apresentamos os movimentos iniciais da constituição da comunidade, articulando a interlocutores teóricos. Na seção três caracterizamos a comunidade em formação; na quarta e quinta, versamos acerca da experiência formativa bem como a descrição dos encontros realizados. Por fim, na sexta seção, pontuamos as percepções emergentes desta experiência.

\section{Movimentos iniciais: refletindo sobre a experiência formativa}

Com base no contexto descrito, descrevemos neste artigo um processo de formação continuada de professores que ensinam Matemática nos Anos Iniciais, seguindo uma estrutura de comunidade aprendente (GALIAZZI et al., 2017; FREITAS, 2010; BRANDÃO, 2005). A contar de Brandão (2005), assumimos comunidade aprendente como sendo todo aquele espaço e tempo 
em que as pessoas se reúnem em rodas de experiências e de saberes, possuindo de qualquer maneira algo de seu, de próprio e de originalmente importante.

Em uma comunidade aprendente todos os participantes, assumidos neste estudo como autores da formação continuada, tem algo a dizer, a ouvir, ensinar e aprender. Com isso, em dezembro de 2018 enviamos a todos os professores dos Anos Iniciais de São Francisco de Paulo (RS) um questionário/convite. Este movimento, teve como objetivo identificar as necessidades formativas dos professores do Município, para assim, iniciar o processo formativo. Foram distribuídos 55 questionários para docentes das redes municipal, estadual e privada. Desse total, 45 questionários retornaram dos quais 43 foram respondidos por professoras que se identificaram do gênero feminino e dois professores, do gênero masculino. A partir das questões introdutórias, podemos traçar as características gerais desse grupo de interesse pela formação. Na Tabela 1, sistematizamos as características gerais do grupo.

Tabela 1: Sistematização das características gerais do grupo de professores

\begin{tabular}{cc}
\hline Questão & Resultado \\
\hline Faixa etária & \# 20 a 30 anos: 2 \\
\# 31 a 40 anos: 8 \\
\# 41 a 50 anos: 18 \\
\# Mais de 50 anos: 17 \\
\# Até 5 anos: 3 \\
\# 6 a 10 anos: 4 \\
\# 11 a 15 anos: 3 \\
\# 16 a 20 anos: 11 \\
\# mais de 21 anos: 24 \\
Tempo de atuação \\
Formação inicial \\
\# Pós-graduação: 26 \\
\# Mestrado: 1 \\
\# 20 horas: 16 \\
\# 40 horas: 29 \\
\hline semanal
\end{tabular}




\begin{tabular}{cc}
\hline Vínculo de trabalho & $\begin{array}{c}\text { \# Rede estadual: } 19 \\
\text { \# Rede municipal: } 16 \\
\text { \# Ambos: } 10\end{array}$ \\
\hline $\begin{array}{c}\text { Localização da Escola em } \\
\text { que trabalha }\end{array}$ & $\begin{array}{c}\text { \# Sede do município: } 24 \\
\text { \# Interior do município: } 21\end{array}$ \\
\hline
\end{tabular}

As informações apresentadas na Tabela 1, nos possibilitou uma primeira aproximação com o grupo de professores que ensinam Matemática nos Anos Iniciais da cidade. Além disso, oportunizou inferir que os professores possuem larga experiência na docência, bem como caracterizam-se como um grupo bastante qualificado, tendo em vista que mais de $50 \%$ possui pósgraduação. Nesse sentido, configurou-se um desafio propor uma formação continuada que atendesse as necessidades de um grupo experiente e qualificado.

A análise do questionário/convite mostrou aos proponentes da formação, que o conjunto de professores desta etapa da escolaridade está dividido em dois grandes grupos, de acordo com a localidade em que trabalham e residem. A partir dessa informação, propomos ao grupo constituído inicialmente de 45 professores - duas comunidades aprendente, uma no interior e outra na sede do Município, no intuito de oportunizar que todos pudessem participar da formação.

Além do movimento de caracterização do grupo de professores que ensinam Matemática nos Anos Iniciais do Ensino Fundamental no Município de São Francisco de Paulo, o questionário buscou identificar as necessidades formativas desses profissionais por meio de questões que objetivaram:

- Rememorar a experiência formativa de cada professor acerca do ensino de Matemática;

- Identificar as dificuldades encontradas pelos docentes deão ensinar Matemática nos Anos Iniciais; e

- Identificar o que cada professor considera importante que seja desenvolvido em uma formação continuada para professores que ensinam Matemática nos Anos Iniciais.

As respostas obtidas a partir das questões elaboradas, de acordo com esses objetivos, estão sistematizadas na Figura 1. 


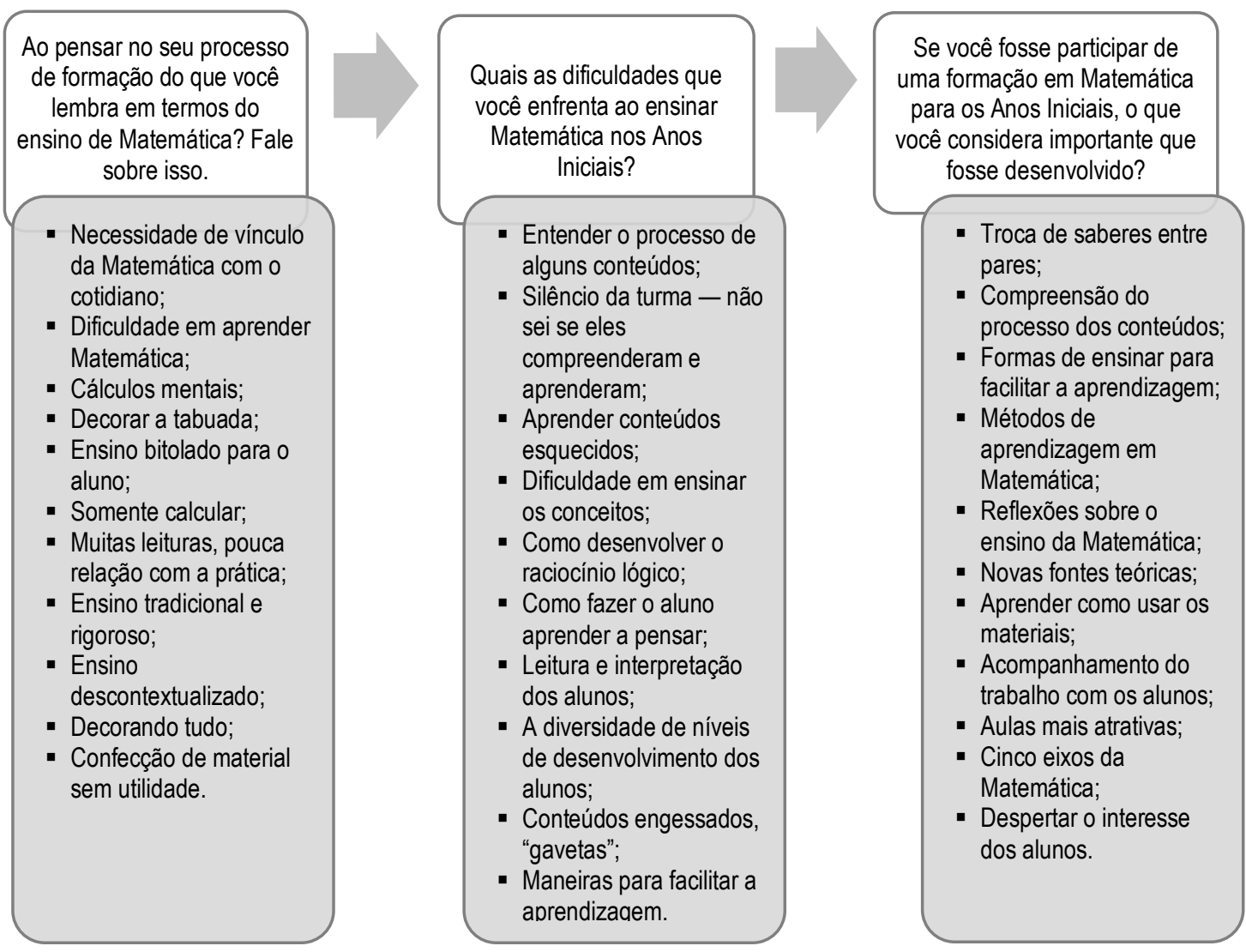

Figura 1: Sistematização das respostas dos professores (Dados da Pesquisa)

A partir dos aspectos sistematizados na Figura 1, destacamos aqueles que serviram, inicialmente, de base para a promoção da formação continuada em comunidade aprendente:

- A necessidade de aulas mais atrativas;

- Formas de ensinar a Matemática que possibilitem facilitar a aprendizagem e motivar o estudante;

- Reflexões sobre o ensino de Matemática e a troca de saberes entre pares.

Com base nesses aspectos e alinhado aos pressupostos teóricos, iniciamos o movimento formativo dos professores em março de 2019. Registra-se que o movimento metodológico da formação, além dos princípios de comunidade aprendente, desenvolvemos uma sequência de atividades fundadas nas metodologias ativas, com o objetivo de problematizar e discutir de forma dinâmica os princípios do Referencial Curricular Gaúcho nesta área do conhecimento.

Identificam-se pontos de convergência entre comunidade aprendente e as metodologias ativas, uma vez que ambas buscam superar a concepção do ensino bancário para uma concepção em que o estudante seja ativo e autônomo em seu processo de aprendizagem (FREIRE, 1987, 
1996). Gallo (2008) reforça essa ideia ao estabelecer a premência de um ensino "que implique um aprendizado criativo e não simplesmente reprodutivo" (p. 128).

Além disso, mesmo que o grupo seja qualificado e experiente, o Referencial Curricular Gaúcho representa mudanças que devem ser incorporadas na prática de todos os docentes, tanto relativas ao ensino quanto à aprendizagem dos estudantes. Nesse sentido, destaca-se que a formação continuada ancorada na concepção de comunidade aprendente e com a utilização de metodologias ativas pode atender às necessidades formativas apontadas no questionário/convite, contribuindo para a qualificação das ações docentes.

De acordo com Moraes e Lima (2012) "questionar o conhecer é problematizar o conhecimento" (p. 14). Nesse sentido, a proposta da comunidade aprendente surge como cenário capaz de suscitar esses questionamentos e problematizações do conhecimento profissional do professor. O questionamento mencionado pelos autores diz respeito às práticas pedagógicas, ao processo de construção dos saberes e aos conceitos matemáticos envolvidos diariamente em sala de aula.

podemos questionar nossa compreensão do significado do aprender. [...] perguntarnos sobre o que significa aprender e sobre os diferentes significados do aprender para outros. [...] Em relação ao mesmo aprender, podemos questionar-nos sobre como agimos quando pretendemos aprender algo. De que modo nos movimentamos quando pretendemos aprender algo, ou quando pretendemos ajudar outros em sua aprendizagem. [...] Tudo pode ser questionado. Tudo pode ser modificado (MORAES e LIMA, 2012, p. 15).

Dessa forma, a incorporação da pesquisa na prática docente assume um viés de "questionamento reconstrutivo voltado para a educação do aluno" (DEMO, 2015, p. 47). Igualmente, a formação docente é preocupação desse estudo sendo construída dentro da própria profissão (NÓVOA, 2009), ou seja, o professor se constrói como profissional a partir de suas experiências.

Partindo desses pressupostos, a interação social proposta por Vygotsky (1991) ocupa função de destaque nesse processo formativo, considerando que os sujeitos aprendem a partir da relação com os outros. Nesse caso, a proposta da comunidade aprendente configura-se como possibilitadora dessa interação e de partilha de experiências entre os professores que, em conjunto, vão se formando e formando uns aos outros.

A utilização das metodologias ativas como procedimento metodológico na formação da comunidade, representa a oportunidade de o professor experenciar novas estratégias de ensino, 
motivando-o a aplicá-las na prática pedagógica em sala de aula. Segundo Trigo e Nunes (2011), a percepção de ensino do professor reflete sobre sua prática profissional; ele tende a reproduzir os métodos educacionais pelos quais foi educado, assim "para que assimilem em sua prática pedagógica diferentes estratégias de ensino é necessário que vivencie, como aluno, essas experiências" (p. 17).

Acredita-se que a tríade pesquisa/estudo, teoria e prática pode contribuir na formação dos professores, pois segundo Becker e Marques (2007), a docência caracteriza-se pela força investigadora do professor que necessita contextualizar o ensino bem como refletir sobre os diferentes trajetos de aprendizagem dos estudantes. Nesse sentido, acontece a assunção do professor pesquisador da sua sala de aula - compartilhamos das premissas elencadas por Becker e Marques (2007) quando destaca a "descentração" como a "capacidade de entender 0 pensamento do outro" (p. 60).

É só na medida em que o professor se coloca na posição de pesquisador em sala de aula que ele consegue superar o seu egocentrismo, entender o pensamento do aluno e coordenar os diferentes pontos de vista que se configuram nesse espaço escolar (MARQUES, 2007, p. 61).

Diante desses pressupostos, a ideia de unir a comunidade aprendente e as metodologias ativas pode promover a movimentação dos professores em prol da investigação contínua de seu fazer pedagógico aliada à colaboração entre colegas de profissão. A inserção do estudo do Referencial Curricular Gaúcho representa a necessidade que o professor tem de apropriar-se das mudanças curriculares para que sejam incorporadas à sua prática pedagógica. Além disso, não se pode ensinar algo sem que seja minuciosamente conhecido.

\section{A comunidade constituída: caracterização dos participantes da formação}

A contar dos movimentos iniciais, que aproximou os pesquisadores dos professores interessados em participar da comunidade aprendente sobre o Referencial Curricular Gaúcho, constituímos um grupo de 21 professores. A referida comunidade, composta por docentes das redes municipal e estadual de São Francisco de Paula (RS), foi dividida em dois grupos: 10 participantes no interior e 11 na cidade. Essa divisão em grupos surgiu a partir do desejo de contemplar os professores do interior tendo em vista a extensão territorial do Município. Normalmente são os docentes do interior que se deslocam para a sede e, dessa vez, os 
proponentes optaram por fazer esse deslocamento e ofertar a formação mais perto da residência e do local de trabalho desses professores.

No que tange à caracterização desses sujeitos, apontamos o tempo de atuação, a graduação e pós-graduação que formam a comunidade. 0 gráfico 1 apresenta o tempo de atuação dos professores.

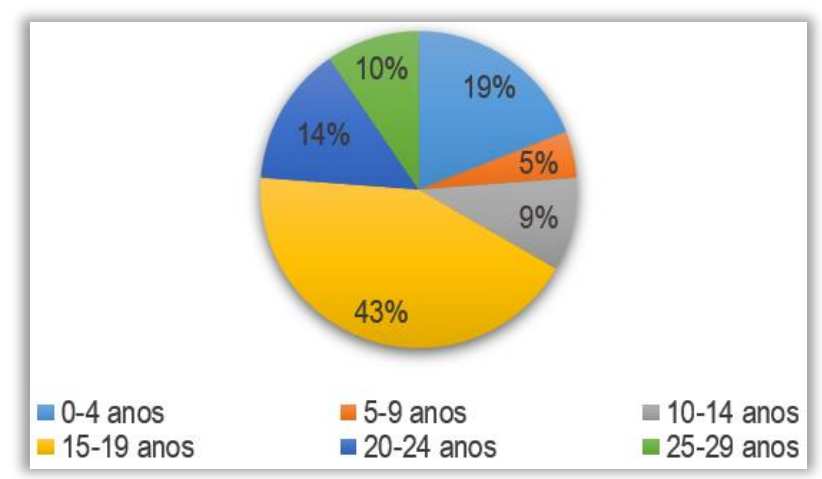

Gráfico 1: Caracterização dos professores em formação: tempo de experiência (Elaboração dos Autores)

Com base no Gráfico 1, percebe-se que, em sua maioria, os participantes da comunidade são professores com mais de 15 anos de experiência profissional. Sendo assim, a formação em comunidade possui o desafio de desacomodar e movimentar esses docentes no sentido de perceber e pensar sobre suas ações pedagógicas direcionadas para as mudanças curriculares atuais, ou seja, "refletir sobre sua prática em suas múltiplas dimensões" (RIO GRANDE DO SUL, 2018, p. 34). Em relação à formação dos professores, o Gráfico 2 mostra a diversidade existente na comunidade.

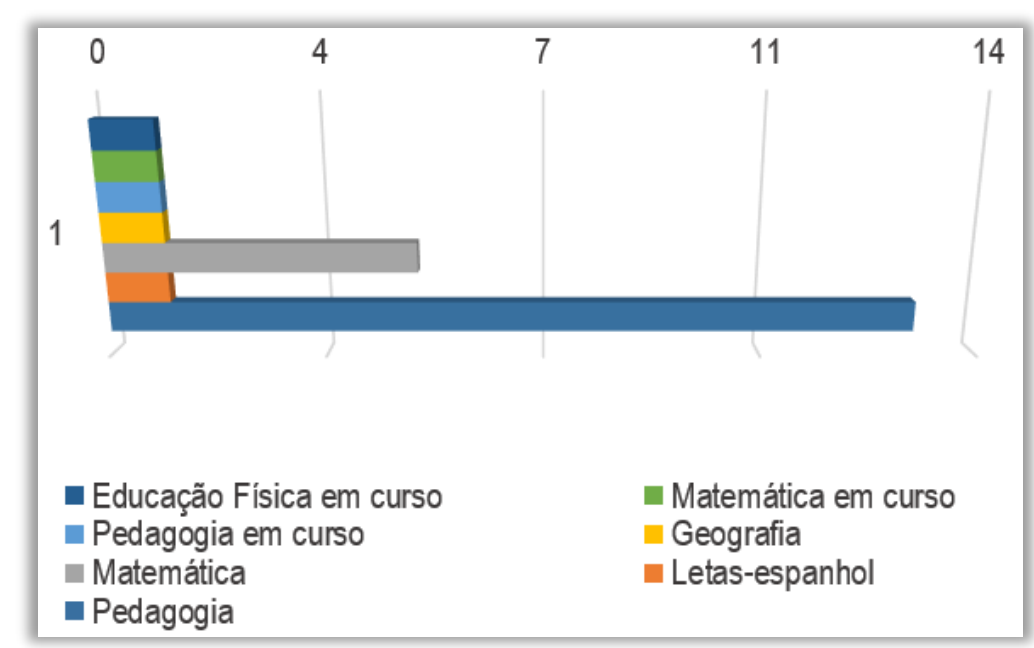

Gráfico 2: Caracterização dos professores em formação: graduação (autora)

No Gráfico 2, observa-se que mais da metade dos docentes possuem graduação em 
Pedagogia. Para além disso, há uma diversidade nas formações sendo que o grupo contém, inclusive, professores que ainda não concluíram sua formação inicial.

A diversidade exprimida nos cursos de graduação é significativamente ampliada quando analisamos a formação em nível de pós-graduação, conforme mostra a Tabela 2.

Tabela 2: Caracterização dos professores em formação: pós-graduação

\begin{tabular}{cc}
\hline Curso de Pós-Graduação & $\begin{array}{c}\text { Quantidade de } \\
\text { Professores }\end{array}$ \\
\hline Administração, Supervisão e Orientação Escolar & 7 \\
\hline Neuropsicopedagogia & 6 \\
\hline Informática & 3 \\
\hline Ensino Religioso & 1 \\
\hline Filosofia e Sociologia & 2 \\
\hline Docência em Educação Infantil e Anos Iniciais & 2 \\
\hline Educação especial e inclusiva & 1 \\
\hline Alfabetização e letramento & 1 \\
\hline
\end{tabular}

Fonte: Dados da Pesquisa

Ademais, a comunidade também possui três participantes cursando especialização em Matemática e dois participantes com Mestrado em Tecnologias concluído. É possível vislumbrar que os professores da comunidade advém de diferentes bases formativas e, com isso, a apropriação do RCG de Matemática dos Anos Iniciais bem como a reflexão acerca de suas práticas retratam o movimento pretendido e necessário para que seja possível o alinhamento entre os saberes dos docentes e as novas mudanças curriculares.

Cabe ressaltar que uma proposta formativa alicerçada nas premissas da comunidade 
aprendente e metodologias ativas não é a solução para todos os problemas enfrentados pelos professores, mas pode representar um caminho para dirimir, em parte, os anseios e desafios enfrentados diariamente em sala de aula. Com isso, acredita-se na qualificação da prática pedagógica e alvitramos melhoras na aprendizagem matemática dos estudantes dos Anos Iniciais. Na próxima seção, relatamos os movimentos que constituíram os encontros de formação realizado com a comunidade.

\section{A experiência formativa}

A contar dos entendimentos descritos ao longo deste artigo bem como das necessidades formativas apontadas pelos professores no questionário/convite, a formação proposta aos grupos fundamenta-se nas concepções da comunidade aprendente (GALIAZZI et al., 2017; BRANDÃO, 2005; FREITAS, 2010) e das metodologias ativas (MORÁN, 2015; DIESEL, BALDEZ e MARTINS, 2017). Registramos que o objetivo principal da formação se consistiu na problematização do Referencial Curricular Gaúcho de Matemática para os Anos Iniciais do Ensino Fundamental. Na Figura 2, descrevemos a estrutura fundante da formação, sua organização e especificidades.

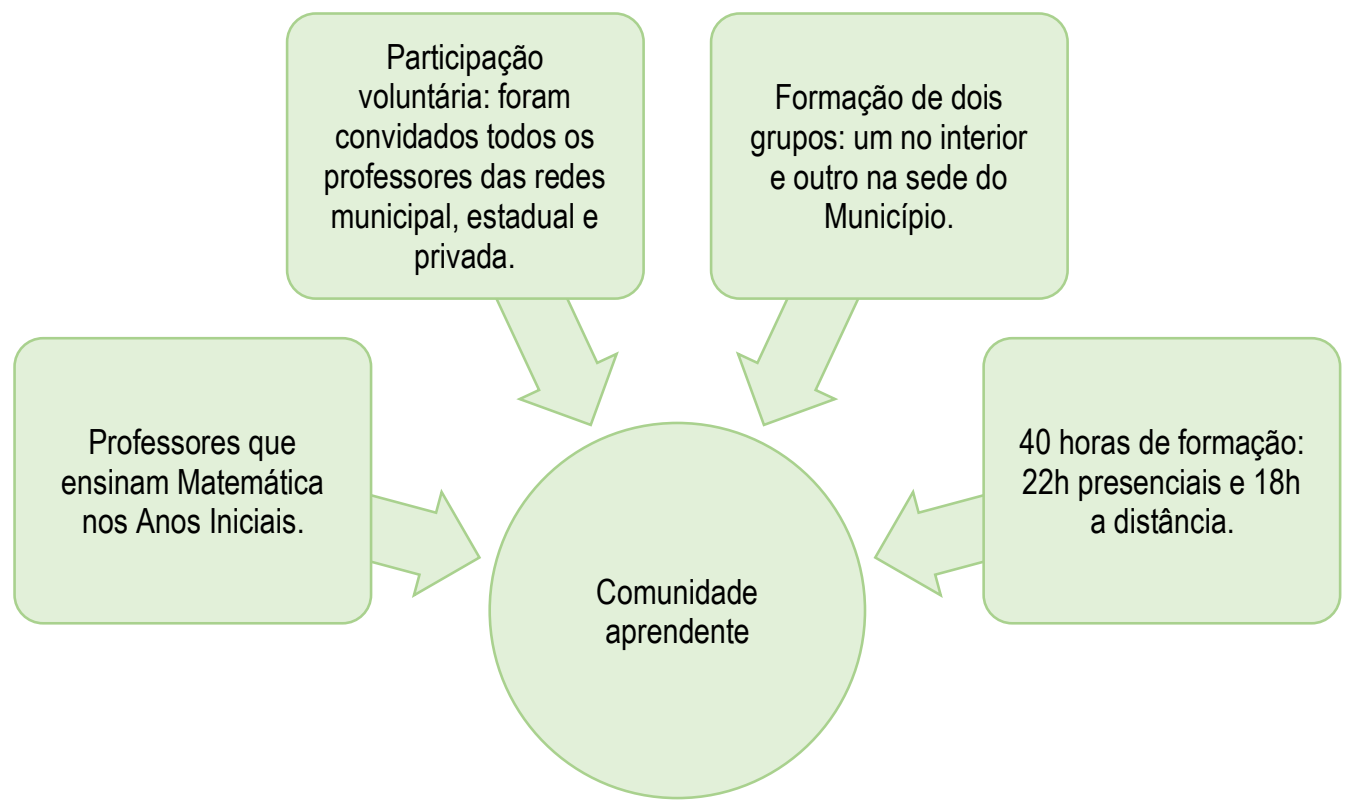

Figura 2: Estrutura da formação (Dados da Pesquisa)

Destacamos que os encontros ocorreram de forma diferente entre o grupo da sede e do interior: Na sede, a comunidade reuniu-se quinzenalmente em encontros com duração de 3 h e no interior, os encontros foram mensais com duração de 6h. Essa diferenciação foi ocasionada a partir da solicitação do grupo do interior tendo em vista a necessidade de deslocamento para 
participação na formação. Além disso, o encontro de encerramento foi coletivo, ou seja, reuniu os dois grupos no intuito de partilhar as experiências formativas bem como confraternizar com a finalização desse momento.

Com base na estrutura exposta, ressaltamos alguns aspectos organizacionais que caracterizam a comunidade em formação:

- As atividades a distância foram realizadas na plataforma do Google Sala de Aula, conforme apresentado na Figura 3. Para tanto, foram criadas duas turmas na plataforma e, para cada uma, as atividades e materiais utilizados nos encontros foram postados. As atividades a distância ocorreram no período entre um encontro presencial e outro no intuito de ampliar as discussões bem como suscitar reflexões e escritas de acordo com os objetivos propostos.

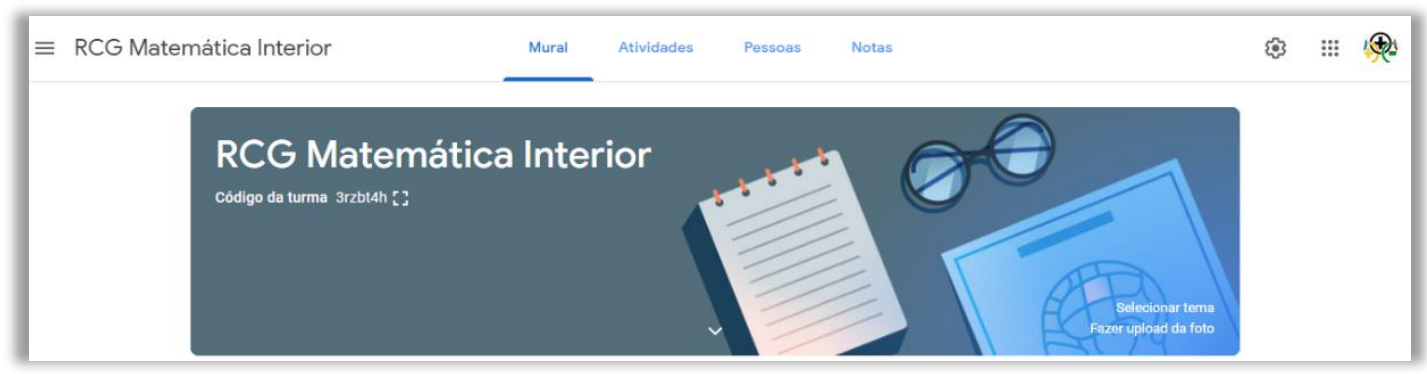

Figura 3: Tela inicial do Ambiente Virtual de Aprendizagem (Dados da Pesquisa)

- A dinâmica e organização de cada encontro foram planejadas de acordo com o caminho percorrido pelo grupo, ou seja, propôs-se uma formação horizontal na qual os participantes e as discussões de cada encontro definiram os próximos passos da comunidade. A Figura 4 apresenta um dos momentos de trabalho da comunidade. 


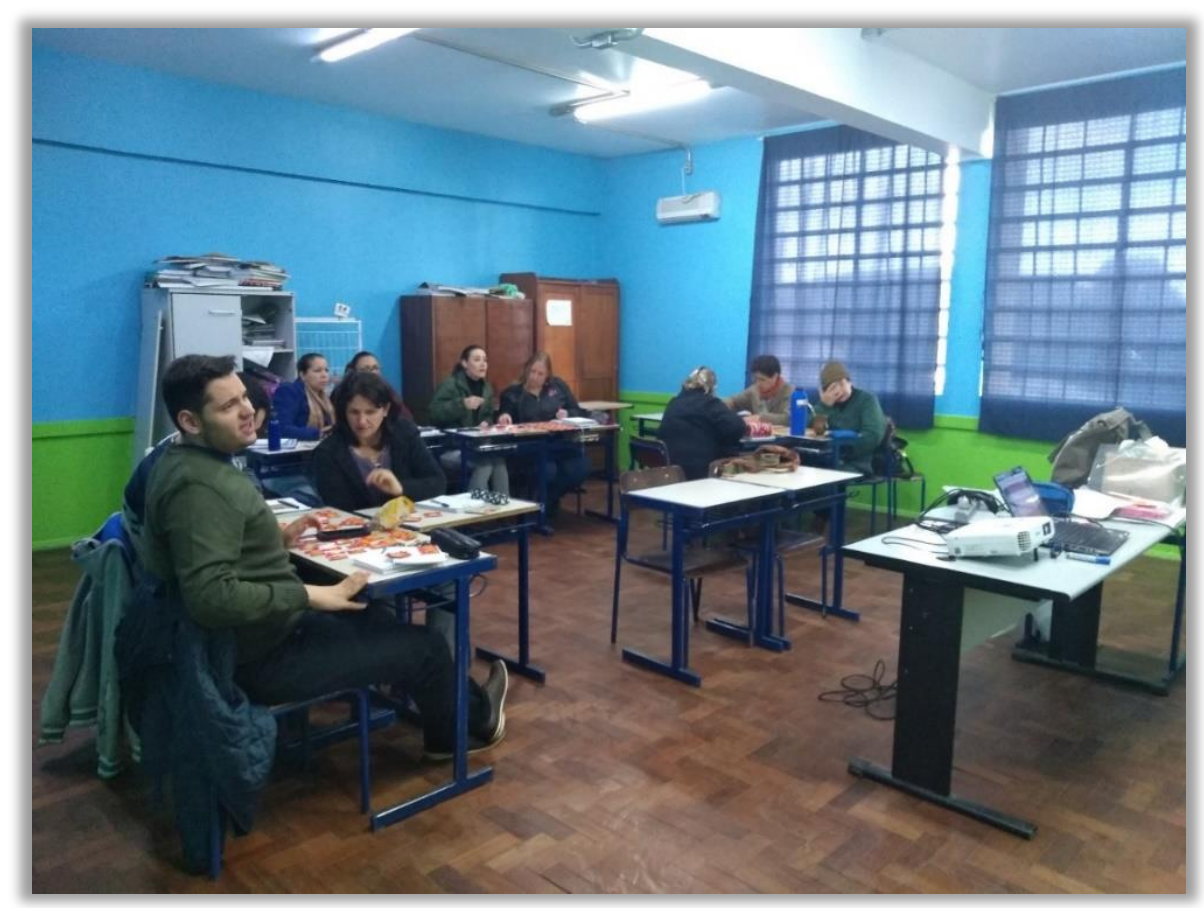

Figura 4: Momento de trabalho da comunidade (Acerva da Pesquisa)

- Proposta de escrita de um "diário de movimentos" - relatos dos encontros escritos por cada participante a partir das discussões e problematizações. A Figura 5 apresenta esses diários de movimentos sendo que, esse material, fez parte do corpus de análise do estudo, a ser apresentado em comunicações futuras.

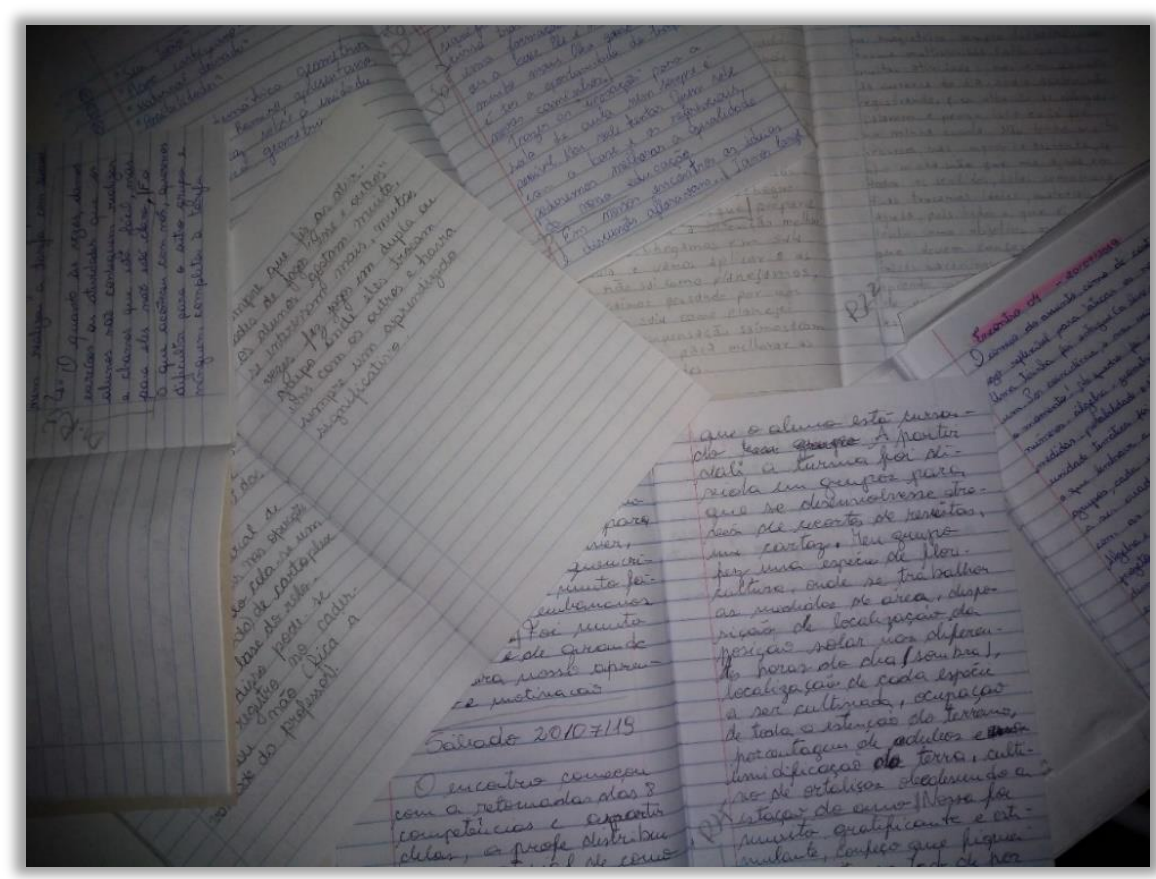

Figura 5: Diários de movimentos (Acerva da Pesquisa)

A partir da estruturação descrita, os encontros formativos da comunidade constituíram-se 
de atividades e discussões voltadas aos preceitos estabelecidos neste artigo bem como estruturadas conforme as necessidades apontadas pelos grupos a cada encontro.

\section{Encontros formativos}

Discutir, partilhar experiências, aprender coletivamente e apreender acerca das mudanças curriculares propostas no RCG para a Matemática nos Anos Iniciais compõem os objetivos fundamentais dos encontros formativos. A seguir, descrevemos, de forma resumida, cada um desses momentos incluindo as atividades realizadas síncrona e assincronamente. 0 material utilizado na íntegra pode ser consultado no Google Drive¹.

\section{Primeiro encontro}

Objetivos: Conhecer e discutir a proposta de formação; problematizar a importância do currículo para a prática docente.

Os participantes foram acolhidos pelos proponentes e ganharam um caderno e um lápis no intuito de utilizá-los para a escrita do diário de movimentos. O texto "flor vermelha de caule verde" foi lido e discutido coletivamente com objetivo de suscitar concepções acerca das práticas pedagógicas dos professores relacionando-as com as ideias centrais trazidas pelo Referencial Curricular Gaúcho. Baseando-se no texto, cada participante foi desafiado a desenhar algo que 0 representasse e, com isso, apresentar-se ao grupo.

Após o momento de apresentação, a proposta de formação foi exposta ao grupo destacando que a ideia central desta comunidade não seria apontar "receitas prontas", mas aprender coletivamente a partir das discussões, das experiências e dos estudos realizados ao longo da formação. A seguir, foram retomados os marcos legais que embasam a Base Nacional Comum Curricular bem como as dez competências gerais descritas por este documento.

Dando continuidade, os participantes foram convidados a dividir-se em cinco grupos e a realizar uma atividade baseada no método world café 2 com trechos de textos referentes ao currículo, às metodologias ativas e à comunidade aprendente. Cada grupo teve a oportunidade de discutir todos os cinco textos e, ao final, houve a socialização dessas discussões por meio da

\footnotetext{
1 Disponível pelo link https://drive.google.com/open?id=1PP4LsJDuxBgej_A8h5-ZMbcdMnO24krq.

2 World café caracteriza-se como uma ferramenta para conversas coletivas e colaborativas com objetivo de pensar e discutir assuntos diversos. Fonte: http://www.theworldcafe.com/about-us/; acesso 2 fev. 2020.
} 
apresentação do cartaz de cada texto.

Ao longo da socialização, o grupo pode complementar as discussões partilhando concepções e ampliando o movimento de pensar sobre as mudanças curriculares e suas implicações na prática em sala de aula. Para finalizar o encontro, apresentamos a ferramenta Google Sala de Aula explicitando seu funcionamento bem como a forma de acesso.

$\mathrm{Na}$ sala de aula virtual, para a atividade assíncrona, o grupo foi convidado a realizar a leitura do texto introdutório da Matemática no Referencial Curricular Gaúcho, páginas 48 a 56, refletindo sobre sua prática a partir de questionamentos disponíveis no ambiente virtual. Além disso, a escrita do diário de movimentos também se constitui de atividade assíncrona.

Segundo encontro:

Objetivos: Discutir e sintetizar as questões as questões desenvolvidas na atividade a distância; identificar e problematizar as competências específicas da área da Matemática apontadas no Referencial Curricular Gaúcho.

Para o segundo encontro, os participantes foram recebidos com adesivos deixados em cima das carteiras. Esses adesivos continham frases retiradas do texto introdutório do Referencial Curricular Gaúcho de Matemática o qual havia sido assunto da atividade assíncrona referente ao encontro anterior. Cada participante foi convidado a ler seu adesivo e houve discussão coletiva acerca das frases. Seguindo o encontro, foi apresentada ao grupo uma síntese das respostas obtidas na atividade proposta na sala de aula virtual com objetivo de valorizar as concepções trazidas pelos professores bem como apontar o direcionamento dado a esse segundo encontro. $A$ partir disso, assistimos ao vídeo "Cotidiano escolar e a Matemática3" e discutimos sobre o quanto a prática pedagógica pode fazer a diferença na aprendizagem dos estudantes.

Tendo por base as respostas obtidas na sala de aula virtual, percebeu-se que uma das questões destacadas pelo grupo consiste no reconhecimento de que a Matemática é uma ciência humana, aspecto que se caracteriza como uma das competências específicas para esta área do conhecimento. Dessa forma, foi proposta uma atividade no intuito de experienciar a competência na prática: dividiu-se os professores em três grupos, cada grupo recebeu uma corda do mesmo tamanho com diversos nós amarrados em distâncias iguais e previamente estabelecidas pela

\footnotetext{
${ }^{3}$ Disponível em https://www.youtube.com/watch?v=DTcYuFWewrg, acesso 2 fev. 2020.
} 
pesquisadora. A tarefa de cada grupo era medir a sala onde nos encontrávamos utilizando a corda e os nós. Após a realização da atividade, discutimos coletivamente as medidas obtidas por cada grupo bem como as estratégias utilizadas para alcançar essas medidas. A pesquisadora comentou com o grupo sobre o surgimento do conceito de número fracionário e sua relação com a atividade desenvolvida pelos professores.

Para encerrar esse momento, foram apresentados slides com as competências específicas da Matemática e discutimos coletivamente quais delas estariam relacionadas com a atividade desenvolvida. Finalizando o encontro presencial, apresentamos ao grupo o ensino sob medida como método possível para utilização em sala de aula tendo em vista que objetiva planejar as atividades de acordo com as necessidades apontadas pelos estudantes. 0 grupo percebeu que este encontro seguiu as ideias estabelecidas pelo método no momento que retomou as respostas das atividades a distância e propôs atividades de acordo com o direcionamento apontado nestas respostas.

Para as atividades assíncronas, além da escrita do diário de movimentos, propusemos reflexões acerca das atividades presenciais de forma a relacioná-las com as competências específicas bem como com a viabilidade de aplicação em sala de aula.

\section{- Terceiro encontro}

Objetivos: Discutir sobre as percepções pessoais acerca do ensino de Matemática; problematizar as competências específicas da Matemática previstas no Referencial Curricular Gaúcho.

Para o terceiro encontro os professores foram acolhidos com um varal de convites dispostos na entrada da sala e cada um pode ler todos e escolher um deles para si. Discutimos coletivamente os convites e as percepções que os professores tiveram ao encontrá-los bem como a viabilidade de acolher os estudantes com uma atividade similar a essa. Após esse momento inicial, a pesquisadora apresentou um feedback do encontro anterior apontando os principais aspectos mencionados pelos professores na atividade a distância.

Seguindo a lógica de que os encontros presenciais são planejados e organizados a partir do direcionamento apontado pelo grupo, as atividades propostas para esse dia vieram ao encontro dos aspectos apontados na atividade a distância. Os professores foram convidados a dividirem- 
se em grupos com três colegas e cada grupo recebeu o material para a atividade: um conjunto de cartas do jogo boole 4 .

A partir disso, foi apresentado um desafio para que cada grupo solucionasse utilizando as cartas recebidas e anotando sua resposta em uma folha. Após a solução, cada grupo apresentou sua resposta explicitando as estratégias que utilizou para resolvê-la. Discutimos coletivamente as respostas e foi proposto o desafio dois com a mesma sistemática ocorrida no primeiro.

Após a discussão das respostas do desafio dois, os professores foram instigados a refletir sobre 0 quanto as estratégias apresentadas pelos colegas na resolução do primeiro desafio contribuíram ou não para que cada grupo solucionasse o segundo desafio. Com isso, ampliamos as discussões acerca da aprendizagem coletiva bem como das possibilidades de oportunizar momentos em que os estudantes construam significados entre pares.

Em continuidade ao encontro, cada grupo foi desafiado a elaborar um desafio boole para que, em seguida, trocassem entre grupos no intuito de solucioná-los. 0 momento de troca e solução dos desafios elaborados pelos grupos foi muito interessante, pois nenhum dos desafios obteve êxito na resolução, ou faltavam informações ou estavam demasiadamente confusos e não havia clareza nos questionamentos a serem respondidos.

Finalizamos esta atividade com uma reflexão e discussão coletiva acerca da importância da empatia, ou seja, o professor precisa pensar como os estudantes enxergam e compreendem as atividades, o que é suficientemente claro para o professor nem sempre é para o estudante.

Finalizamos o encontro presencial refletindo e estabelecendo relações entre a atividade desenvolvida e as competências específicas de Matemática no Referencial Curricular Gaúcho, bem como sobre a viabilidade de utilização destes desafios em sala de aula. A pesquisadora relatou uma experiência pessoal em que o desafio boole foi utilizado para auxiliar alunos com dificuldades de aprendizagem e, a partir disso, um livro com desafios foi elaborado por esses alunos e distribuído na escola em que estudavam.

Para a atividade assíncrona, os professores foram desafiados a escolher uma prática de sala de aula para trazer no próximo encontro e partilhar com os colegas acrescido da escrita no diário de movimentos.

\footnotetext{
4 Visam o desenvolvimento do raciocínio lógico através da resolução de enigmas construídos sobre estruturas lógicomatemáticas. Fonte: https://jogosboole.com.brl. Acesso 02 fev. 2020.
} 


\section{Quarto encontro}

Objetivos: Partilhar experiências profissionais; estabelecer relações entre a prática profissional e as competências e habilidades de Matemática do Referencial Curricular Gaúcho.

No quarto encontro os professores foram acolhidos com o vídeo "Reflexões sobre sistema de educação e trabalho5", com objetivo de suscitar discussões acerca do quanto a escola, e mais especificamente as práticas docentes, podem transformar o sujeito e a sociedade. Iniciamos a rodada de partilha de experiências e, a cada apresentação e expor a atividade trazida por um colega, discutimos e refletimos sobre as diferentes formas de exploração e utilização da atividade estabelecendo relação com as competências específicas e habilidades propostas para a área de Matemática.

Além disso, ampliamos as discussões no sentido de perceber que cada uma das atividades poderia ser utilizada em diferentes anos do Ensino Fundamental, mas com grau de complexidade adequado a cada um deles. Com isso, emergiu a recursividade do currículo, ou seja, as habilidades são propostas ano a ano da escolaridade ampliando a complexidade, retomando, aprofundando e consolidando os conceitos.

Para finalizar a rodada de partilha, a pesquisadora relatou a sua experiência a partir da utilização do texto Carta da Terra. Para a atividade assíncrona, além da escrita do diário, os professores foram desafiados a refletir sobre a recursividade do currículo aliada à partilha ocorrida no encontro presencial e, a partir disso, escolher uma das atividades, descrevê-la e estabelecer possibilidades de sua utilização do $1^{\circ}$ ao $5^{\circ}$ ano relacionando com habilidades, competências específicas e competências gerais.

\section{Quinto encontro}

Objetivos: Reconhecer as unidades temáticas da Matemática; estabelecer relações entre unidades temáticas, competências específicas e habilidades.

Os professores foram acolhidos com diferentes papéis em cima de uma mesa, todos voltadas para baixo e cada participante sorteou um deles. Ao virar seu papel, descobriam que consistiam em tirinhas matemáticas, que foram lidas e discutidas coletivamente estabelecendo

\footnotetext{
${ }^{5}$ Disponivel em https://www.youtube.com/watch?v=K4Foovfdb-E, acesso 2 fev. 2020.
} 
relações com as competências específicas de Matemática bem como com as unidades temáticas trazidas pelo Referencial Curricular Gaúcho.

Em continuidade, o grupo foi desafiado com uma Tempestade de ideias ${ }^{6}$ sobre as unidades temáticas: o objetivo consistia em trazer à tona, de forma espontânea, as concepções e ideias acerca de cada uma das cinco unidades e os aspectos citados foram anotados em uma tabela desenhada no quadro branco da sala. A partir disso, os professores foram divididos em cinco grupos e, para cada grupo, foi distribuído um material contendo a descrição da unidade temática apresentada na Base Nacional Comum Curricular, bem como explicitando as diferenças entre essa descrição e aquela presente nos Parâmetros Curriculares Nacionais.

Com esse material em mãos, cada grupo recebeu a tarefa de representar a sua unidade temática da forma mais criativa possível, foram disponibilizados diferentes materiais para os grupos: revistas, cola, canetinhas, cartolina, lápis de cor etc.

Por fim, as representações foram socializadas ao grande grupo e comparadas as concepções e ideias trazidas na atividade inicial. Para a atividade assíncrona, foi solicitada aos professores a sistematização entre as tirinhas matemáticas, as unidades temáticas, competências específicas e habilidades. Além disso, a escrita do diário de movimentos.

\section{Sexto encontro}

Objetivos: Perceber a gradação das habilidades ao longo dos Anos Iniciais bem como as mudanças propostas pelo Referencial Curricular Gaúcho; estabelecer relações entre atividades, unidades temáticas e habilidades; e experenciar atividades possíveis de aplicação em sala de aula.

Para o sexto encontro, os professores foram acolhidos com a organização diferenciada do espaço da formação tendo em vista que utilizamos o método rotação por estações ${ }^{7}$. As atividades organizadas para cada uma das cinco estações estão relacionadas às unidades temáticas estabelecidas no Referencial Curricular Gaúcho, para cada uma delas havia uma estação.

Os professores foram divididos em grupos e passaram por todas as estações

6 Ferramenta que possibilita a liberação e ampliação de ideias a partir de suas associações. Fonte: https://bibliotecas.sebrae.com.br, acesso 2 fev. 2020.

${ }^{7}$ Método ativo em que os estudantes circulam pelas estações de atividades com objetivo de resolvê-las e discuti-las. Fonte: https://home.unicruz.edu.br, acesso 2 fev. 2020. 
solucionando as atividades. Após finalizar a rotação, cada uma das atividades foi discutida coletivamente estabelecendo relações com as competências específicas de Matemática bem como com as habilidades previstas no documento curricular. A discussão foi ampliada no sentido de perceber que cada uma das atividades poderia ser explorada nos diferentes anos do Ensino Fundamental, com grau de complexidade de acordo com cada ano.

Essas discussões foram apoiadas no material utilizado no último encontro sobre as unidades temáticas, bem como no material produzido pela pesquisadora acerca de um exemplo de recursividade nas habilidades de Matemática nos Anos Iniciais. Para a sala de aula virtual, os docentes foram convidados a refletir sobre as atividades desenvolvidas no encontro escrevendo suas percepções num relatório bem como instigados a assistir ao vídeo "Quando sinto que já sei8", anotando frases e/ou expressões que considerassem importantes para serem levados no último encontro presencial. Além disso, houve a escrita dos diários.

\section{Sétimo encontro}

Objetivos: Perceber e valorizar habilidades pessoais bem como necessidade de ajuda; retomar aspectos da formação apontando aprendizagens; partilhar experiências; confraternizar com o grupo.

O último encontro da comunidade foi realizado de forma coletiva, ou seja, reunimos o grupo da sede e do interior no intuito de partilhar as experiências formativas e confraternizar com essa caminhada tão especial da comunidade aprendente.

Para a acolhida utilizamos a atividade "posso ajudar/preciso de ajuda", quando cada professor recebeu dois post-its: um deles para escrever o que poderia ajudar os colegas e outro para escrever o que precisaria de ajuda. Montamos um cartaz com os post-its escritos pelos professores e cada um pode falar sobre sua necessidade e disponibilidade reforçando a ideia de que aprendemos na interação social e precisamos valorizar as habilidades individuais.

Em continuidade, apresentamos e refletimos sobre o feedback da formação apontando momentos significativos. A partir disso, o professor orientador desta pesquisa realizou uma partilha de experiência e conversamos sobre a importância do professor, da formação continuada

\footnotetext{
${ }^{8}$ Disponivel em https://www.youtube.com/watch?v=LFBrGC5tIIY, acesso 2 fev. 2020.
} 
significativa e da valorização das experiências profissionais de cada professor.

Seguindo o encontro, propusemos rodas de conversa entre os professores: dividiram-se em grupos contendo colegas do interior e da sede. Nesses grupos, cada professor relatou aos demais as suas percepções da experiência formativa e, para encerrar, deveriam elaborar uma apresentação criativa das aprendizagens desenvolvidas ao longo de toda a formação bem como escrever uma carta destinada a colegas professores que pretendessem participar de uma formação como esta que estávamos finalizando. As apresentações foram socializadas e as cartas recolhidas para arquivo da pesquisadora.

Como atividade final, fizemos uma rodada de conversa sobre o vídeo que os participantes assistiram destacando aspectos que consideraram importante e discutindo sobre a realidade apresentada no vídeo e a realidade das nossas escolas. Como encerramento, foi ofertado um almoço aos professores para socializarmos o término da comunidade aprendente. Cabe destacar que os professores demonstraram o desejo de permanecer com a comunidade aprendente para que pudéssemos continuar nos encontrando, estudando e aprendendo coletivamente.

\section{Para além das considerações finais: o que percebemos com está experiência formativa}

Refletir e escrever considerações sobre essa experiência formativa representa um desafio para os pesquisadores devido a dois grandes aspectos: a subjetividade envolvida na experiência e a apresentação/estruturação da mesma. Em relação à subjetividade, assinalamos que as concepções, discussões, percepções e aprendizagens emergentes desta comunidade em formação são únicas e singulares, isto é, os entendimentos aqui apresentados representam exclusivamente esta comunidade, esta experiência e estes pesquisadores. Qualquer outro pesquisador, com este mesmo grupo, teria compreensões diferentes assim como qualquer outro grupo, com estes pesquisadores, resultaria em percepções distintas. A comunidade representa um espaço-tempo de escuta, acolhimento e pertencimento, ou seja, a dinâmica oportuniza que os participantes se sintam à vontade para discutir, refletir e expor suas opiniões e saberes. Nesse sentido, a sensibilidade do pesquisador é fundamental, pois é por meio dela que as concepções e aprendizagens emergentes serão reconhecidas e compreendidas.

O segundo aspecto, referente à apresentação/estruturação da experiência formativa, diz respeito à preocupação que temos em descaracterizar essa experiência como uma "receita pronta", que basta seguir passo a passo e o resultado será igualmente satisfatório. A ideia da 
comunidade aprendente é inversa ao entendimento de que uma mesma formação pode ser desenvolvida com diferentes grupos em distintos lugares, obtendo resultados iguais. Não é uma experiência formativa vertical, que possa ser "aplicada" por um formador/professor, mas uma proposta horizontal, na qual formadores e participantes direcionam os encontros de acordo com as necessidades apontadas pelo grupo. Todos ensinam e todos aprendem a partir das experiências individuais e das reflexões emergentes ao longo dos encontros.

A partir da experiência vivida, registramos a necessidade de embasar a formação continuada nos documentos curriculares, bem como nas experiências profissionais dos docentes. Esse movimento de entrelaçamento entre teoria (currículo - as expectativas) e prática (ação pedagógica - colocar o currículo em ação) pode representar uma alternativa para 0 aperfeiçoamento da ação docente.

Apontamos a formação de professores no coletivo como instrumento instigador de reflexão possibilitando que os professores (re)pensem suas ações a partir da partilha de experiências e da discussão coletiva. Nesse sentido, a valorização dos saberes trazidos por cada docente representa o ponto de convergência entre suas concepções e as novas construções possíveis a partir das experiências vividas/discutidas na formação. Para além disso, a utilização de metodologias ativas na formação oportuniza que os professores experenciem diferentes estratégias que podem contribuir no processo de ensino e aprendizagem.

Reforçamos a importância da participação ativa dos professores no direcionamento e estruturação da formação, pois um espaço que aborde as percepções e anseios trazidos pelo grupo, torna-se potencialmente mais interessante e significativo. Reconhecemos que propor uma formação para colegas de profissão é sempre desafiante, ainda mais quando o grupo possui larga experiência docente e ampla base formativa. Sendo assim, a participação do grupo auxilia 0 formador no sentido de compreender as necessidades abordando-as da melhor maneira possível.

Indicamos que experenciar as atividades e métodos bem como partilhar experiências e anseios constituíram-se como algumas das potencialidades nesta proposta de formação em comunidade. A ideia de formar-se uns com os outros de modo colaborativo, sem que fossem apresentadas "receitas prontas", fortaleceu os laços entre os participantes, criando um ambiente de confiança para expressar-se e discutir aspectos que considerassem relevantes. Esse sentimento de pertencimento contribuiu para que os professores expressassem suas dúvidas de forma tranquila e segura ampliando as discussões e aprendizagens. 
Em contrapartida, a utilização do ambiente virtual de aprendizagem (AVA) não surtiu 0 resultado esperado. Embora a proposta tenha incluído atividades a distância, percebeu-se que a participação e engajamento foi significativamente mais relevante nos encontros presenciais do que nas discussões propostas no ambiente virtual de aprendizagem.

Cabe ressaltar que as mudanças curriculares estão a mercê do trabalho do professor, ou seja, essas mudanças somente alcançarão as salas de aula e os estudantes se os docentes assim o fizerem. Nessa lógica, a formação continuada assume papel de destaque, pois caracteriza-se como momento capaz de trazer à tona os anseios e preocupações do professor possibilitando que sejam discutidos, estudados e refletidos de forma coletiva.

\section{Referências}

BECKER, Fernando; MARQUES, Tania Beatriz Iwaszko. (Org.). Ser professor é ser pesquisador. Porto Alegre: Mediação, 2007

BRANDÃO, Carlos Rodrigues. Encontros e caminhos: formação de educadoras (es) ambientais e coletivos educadores. Brasília: MMA, Diretoria de Educação Ambiental, 2005.

BRASIL. Ministério da Educação. Secretaria de Educação Básica. Base Nacional Comum Curricular. Educação Infantil e Ensino Fundamental. Brasília: MEC/SEB, 2017.

DEMO, Pedro. Educar pela pesquisa. Campinas: Autores Associados, 2015.

DIESEL, Aline; BALDEZ, Alda Leila Santos; MARTINS, Silvana Neumann. Os princípios das metodologias ativas de ensino: uma abordagem teórica. Revista Thema, v. 14, n. 1, p. 268-288, jan./mar. 2017.

FREIRE, Paulo. Pedagogia da autonomia: saberes necessários à prática educativa. São Paulo: Paz e Terra, 1996.

FREIRE, Paulo. Pedagogia do oprimido. 17. ed. São Paulo: Paz e Terra, 1987.

FREITAS, Diana Paula Salomão de. A perspectiva da comunidade aprendente nos processos formativos de professores pesquisadores educadores ambientais. 2010. 225f. Dissertação (Mestrado em Educação Ambiental) Instituto de Educação. Universidade Federal do Rio Grande.

GALIAZZI, Maria do Carmo; FEEITAS, Diana Paula Salomão de; LIMA, Cleiva Aguiar de; COUSIN, Claudia da Silva; SOUZA, Moacir Langoni de; CUPELLI, Rodrigo Launikas. Narrativas de comunidades aprendentes em Educação Ambiental. Ambiente \& Educação, Rio Grande, v. 22, n. 2, jul./dez. 2017.

GALLO, Silvio. O problema e a experiência do pensamento: implicações para o ensino de filosofia. In: BORBA, Siomara; KOHAN, Walter. (Org.). Filosofia, aprendizagem, experiência. Belo Horizonte: Autêntica, 2008, p. 115-130. 
MORAES, Roque; LIMA, Valderez Marina do Rosário. (Org.). Pesquisa em sala de aula: tendências para a educação em novos tempos. Porto Alegre: EdPUCRS, 2012.

MORÁN, José. Mudando a educação com metodologias ativas. In: Coleção mídias contemporâneas. Convergências Midiáticas, Educação e Cidadania: aproximações jovens. Ponta Grossa: Foca Foto-PROEX/UEPG, 2015, p. 15-33.

NÓVOA, António. Para una formación de profesores construida dentro de la profissión. Revista de Educación, n. 350, p. 203-218, sep./dic. 2009.

RIO GRANDE DO SUL. Secretaria de Estado da Educação. Departamento Pedagógico. Referencial Curricular Gaúcho: Matemática. Porto Alegre: SEE/DP, 2018.

TRIGO, Carmen; NUNES, Wallace Vallory. Experimentos didáticos no ensino da Matemática: orientações pedagógicas. Rio de Janeiro: IFRJ, 2011.

VYGOTSKY, Lev Semenovich. A formação social da mente: o desenvolvimento dos processos psicológicos superiores. Tradução de José Cipolla Neto, Luis Silveira Menna Barreto, Solange Castro Afeche. São Paulo: Martins Fonte, 1991. 